\title{
Application of nanomaterial graphene oxide on biochemical traits of Milk thistle (Silybum marianum $L$.) under salinity stress
}

\author{
Sara Safikhan ${ }^{1}$, Mohammad Reza Chaichi $^{2}$, Korous Khoshbakht $^{{ }^{*}}$, Abbas Amini $^{3}$, Babak Motesharezadeh $^{4}$ \\ ${ }^{1}$ Department of Agroecology, Shahid Beheshti University, Environmental Sciences Research Institute, Shahid \\ Beheshti University, Evin, Tehran, Iran \\ ${ }^{2}$ Department of Crop Science, College of Agriculture, California State University, Pomona, USA \\ ${ }^{3}$ Department of Computing, Engineering, and Mathematics, Western Sydney University, Kingwood Campus, Locked \\ Bag 1797, Perth, NSW 2751, Australia \\ ${ }^{4}$ Department of Soil Science and Engineering, College of Agriculture and Natural Resources, University of Tehran, \\ Karaj, Iran
}

*Corresponding author: k-khoshb@sbu.ac.ir

\begin{abstract}
In recent years, application of engineered nanomaterials, in particular carbon-based nanostructures, has been initiated in agriculture. To better understand the effects of nanomaterials on plants, four concentrations of graphene oxide $(0,0.01,0.05$, $0.1 \%)$ in soil was studied on growth and biochemical traits of Milk thistle under four saline stress $(0,4,8,12 \mathrm{dS} / \mathrm{m}) \mathrm{conditions}$ in greenhouse. A completely randomized block design with a factorial treatment arrangement was employed with three replications. The result showed under both saline and control (non-saline) conditions, the maximum plant height ( $3.7 \%$ and $20 \%$ in control and saline conditions, respectively), total biomass ( $17 \%$ and $8.2 \%$ in control and saline conditions, respectively), and chlorophyll content ( $8 \%$ and $5 \%$ in control and saline conditions, respectively), were achieved for plants with graphene oxide (GO) application. By increasing the salinity level, plants treated with $0.01 \%$ concentration of graphene oxide produced the highest total biomass ( 518 $\mathrm{mg}$ ) under $12 \mathrm{dS} / \mathrm{m}$ salinity levels. Also, maximum quantum efficiency of PSII, performance index, and membrane stability index decreased due to salinity stress. Proline and soluble carbohydrates noticeably increased by saline water treatments. Graphene oxide alleviated salt stress-induced damage through increasing plant growth, plant height, chlorophyll content, photosystem efficiency, performance index, membrane stability index, proline and soluble carbohydrate content. Also graphene oxide increased cell water potential through enhancing the net concentration of solutes in plant cells. Graphene nanomaterials could ameliorate the salt stress in Milk thistle plant. Graphene oxide application could be commercially and economically beneficial for Milk thistle production under control and saline conditions.
\end{abstract}

Keywords: Graphene Oxide, Milk thistle, Pigment, Soluble Carbohydrates, Fluorescence.

Abbreviations: EC_electrical conductivity, FO_initial fluorescence, Fm_maximum fluorescence, FV_variable fluorescence, Fv/Fm_ maximum quantum efficiency of PSII, GO_graphene oxide, IAA_Indole-3-acetic acid, MSI_Membrane stability index, PI_ performance index, PSII_photosystem II, QA_acceptor quencher A, ROS_Reactive Oxygen Species.

\section{Introduction}

The beneficial potentials of nanotechnology in agriculture to improve crop productivity, has been recognized, in the past few years. Recent researches on this subject can be found in the literature (Parisi et al., 2015, Rosa et al., 2016; Ren et al., 2016; Cheng et al., 2016). Examples of applications of nanomaterials in agriculture are in nutrient management, genetic improvement (Torney et al., 2007), plant disease treatment (Park et al., 2006), and plant growth promotion among others (Arora et al., 2012). Graphene oxide (GO) is a water-soluble derivative of graphene and has been extensively used as a precursor of graphene-based nanoparticle composites (Geim, 2009). Some experiments were conducted on the application of GO in agriculture in recent years. This material has shown high potential in soil and crop improvement under stressed conditions. The beneficial effects of GO application on crop growth and development have been reported by Anjum et al. (2014) on faba bean; Hu et al. (2014) on wheat; Zhang et al., (2015) on tomato; and Ren et al., (2016) on maize. Up to $65 \%$ of patients with liver disease may use botanical preparations in the United States and Europe (Loguercio and Festi, 2011). Milk thistle (Silybum marianum L.) is a known medicinal plant belonging to the Asteraceae family, originated in the Mediterranean Basin. Silymarin, a derivative of Milk thistle, has been used as a herbal medicine to treat liver diseases for more than 2000 years (Afshar et al., 2014). Salinity stress is one of the most devastating stressful environments for plant growth and production (Ashraf and Foolad, 2007). Salinity 
causes a range of harmful effects such as inhibition of photosynthetic rate, chlorophyll content, and damage to plasma membrane permeability and other metabolic disturbances (Karimi et al., 2005). Plant responses to salinity depend on photosystem II (PSII) response to this stress (Kalaji and Guo, 2008). Exogenous application of nanomaterials is one of the recent strategies to overcome the salt-induced damaging effects on plant growth and development. Survival under the stressful condition depends on the plant ability to perceive the stimulus, generate and transmit signals, and instigate biochemical changes that regulate the metabolism accordingly (Hasegawa et al., 2000). Salt stress negatively affects biological and physiological processes of plants via inducing water deficiency, osmotic stress, nutritional imbalance and ionic toxicity (Campanelli et al., 2013), eventually resulting in the structural damage of plant cell, photosynthesis inhibition, growth restriction, or even death (Li et al., 2014).

To date, there is not any information about the application of graphene oxide on Milk thistle growth and other characteristics under saline condition. In our study, we mainly focused on the improved plant growth, photosystem efficiency and biochemical traits of Milk thistle as affected by Graphene Oxide under salinity stress condition.

\section{Results and discussion}

\section{Plant height}

Interaction of saline water $\times \mathrm{GO}$ indicated that the maximum plant height $(22.98 \mathrm{~cm})$ was achieved in control $\times 0.01 \% \mathrm{GO}$. Plant height increased by GO application across all salinity levels. Salinity stress decreased plant height, however, application of GO increased plant height of Milk thistle at each salinity level (Fig. 1). Ren et al., (2016) stated that application of sulfonated graphene with $50 \mathrm{mg} / \mathrm{l}$ significantly improved plant height in maize seedlings.

\section{Plant biomass}

At control and saline treatments, the higher Milk thistle biomass weight was achieved for plants with $\mathrm{GO}$ application (Fig. 2). Under control (non-saline) condition, application of $\mathrm{GO}$ at $0.05 \%$ concentration produced the maximum biomass dry weight $(2389 \mathrm{mg})$. In contrast, at saline conditions, application of $0.01 \%$ concentration of GO produced the highest total biomass dry matter $(742.7 \mathrm{mg})$ under $12 \mathrm{dS} / \mathrm{m}$ salinity level (Fig. 2). The reduction in plant growth under salinity stress is explained by adverse impacts of extreme salinity on the ion homeostasis, water balance, mineral nutrition and photosynthetic carbon metabolism (Zhu 2001; Yusuf et al., 2007). Reduction in plant growth due to salinity was reported in previous studies on Rice (Nemati et al., 2011; Nounjan and Theerakulpisut, 2012), Barley (Ali et al., 2011), and Periploca sepium (Sun et al., 2011). The advantage of the low concentration of GO in our result can be explained by its effects on improving the Indole-3-acetic acid (IAA) biosynthesis and concentration, as well as promoting the root growth and elongation in plant (Cheng et al., 2016). Promoting the root and biomass growth is due to the alleviation of oxidative stress mediated by GO, which was directly shown by ROS (Reactive Oxygen Species) level at low concentrations of GO (Ren et al., 2016).

\section{Chlorophyll Content}

The highest concentration of total chlorophyll in control and all salinity treatments was achieved by application of GO with $0.01 \%$ concentration. Larue et al., (2012) reported chlorophyll increment $(50 \mathrm{mg} / \mathrm{l})$ in wheat plantlets when exposed to MWCNTs for 7 days.

Our results indicated significant decreases in chlorophyll concentration under salinity stress which agrees with previous reports on Lentil (Turan et al., 2007) and Bambara groundnut (Taffouo et al., 2010). Hu et al., (2014) described that chlorophyll content in wheat shoots improved by graphene-humic acid treatment. Similarly, exposure of different nanomaterials also increased the chlorophyll contents in soybean (Venkatachalam et al., 2016).

\section{Photosystem II (PSII) efficiency}

Salt stress caused a reduction in maximum quantum efficiency of PSII (calculated from Fv/Fm) and photosystem I (PI). The maximum Fv/Fm and PI were obtained from control condition and minimum amount was achieved from $12 \mathrm{dS} / \mathrm{m}$ (Table 2). Salt stress may have several effects on PSII activity, one of which may be enhanced several inactive reaction centers where electrons cannot be transported out of reduced $\mathrm{QA}$ (acceptor quencher A) and thus higher measured F0 (initial fluorescence). Another possibility is low energy transfer from LHCII to PSII reaction center and thus higher fluorescence from LHCII which may have been caused by the dissociation of LHCII from the PSII core (Havaux, 1993). The low Fv/Fm values in Milk thistle under saline condition (Table 2) could have resulted from the inactivity of the reaction centers, which may favor higher energy dissipation in the form of heat and fluorescence, as deduced from the high Fv/Fm values. The Fv/Fm ratio is usually used as an indicator of the photo-inhibitor or other injury caused to the PSII complexes (Rohacek, 2002). Exogenous foliar application of GO significantly increased chlorophyll a fluorescence of Milk thistle by increasing PI (Table 2). The Performance of PI Index is an indicator of sample vitality of photosynthesis and has three components. These components present the force due to the concentration of active reaction centers, including the light (related to the quantum yield of primary photochemistry) and the dark reactions. The nanomaterials also affect the electron transport, and energy pathways (Aken, 2015).

\section{Membrane stability index (MSI)}

Table 3 shows that effect of salinity and GO on the membrane stability index (MSI) were significant. Membrane stability index (MSI) was significantly affected by salinity and followed a decreasing trend as the salinity levels increased (Table 3). However, with GO application (especially at $0.01 \%$ concentration), membrane stability index significantly increased. Desiccation of plant cells causes cell membrane leakage of ions and electrolytes (Bandurska, 2001). Modifications of lipid structure of plasma membranes are essential in maintaining membrane fluidity, integrity, and 
Table 1. Physicochemical properties of GO utilized in this study.

\begin{tabular}{ll}
\hline Color & Black \\
Form & Powder \\
\hline X-Ray Diffraction & Conforms \\
Carbon $(C)$ & $96 \%$ \\
Oxygen (O) & $2 \%$ \\
Surface area & $110 \mathrm{~m}^{2} / \mathrm{g} \mathrm{(BET)}$ \\
Conductivity & $1.5 \mathrm{E}+05 \mathrm{~S} / \mathrm{m}$ (pressed pellets) \\
Bulk density & $0.2 \mathrm{~g} / \mathrm{mL}$ \\
\hline
\end{tabular}

Table 2. Mean table of growth characteristics, chlorophyll, and chlorophyll a fluorescence in Milk thistle as affected by salt stress and GO.

\begin{tabular}{|c|c|c|c|c|c|}
\hline Treatments & $\begin{array}{l}\text { Plant height } \\
(\mathrm{cm})\end{array}$ & $\begin{array}{c}\text { Total biomass } \\
\text { (mg) }\end{array}$ & $\begin{array}{c}\text { Total chlorophyll (mg/g } \\
\text { F.W.) }\end{array}$ & $\mathrm{PI}$ & $\mathrm{Fv} / \mathrm{Fm}$ \\
\hline \multicolumn{6}{|l|}{ Salt stress } \\
\hline $0 \mathrm{dS} / \mathrm{m}$ & $22.689 a$ & $2156.830 \mathrm{a}$ & $1.264 \mathrm{a}$ & $3.393 \mathrm{a}$ & $0.837 \mathrm{a}$ \\
\hline $4 \mathrm{dS} / \mathrm{m}$ & $20.860 \mathrm{~b}$ & $1701.420 \mathrm{~b}$ & $1.213 \mathrm{~b}$ & $3.131 b$ & $0.816 \mathrm{~b}$ \\
\hline $8 \mathrm{dS} / \mathrm{m}$ & $15.155 \mathrm{c}$ & $944.250 \mathrm{c}$ & $1.071 \mathrm{c}$ & $2.595 \mathrm{c}$ & $0.796 \mathrm{c}$ \\
\hline $12 \mathrm{dS} / \mathrm{m}$ & $14.136 \mathrm{~d}$ & $696.830 \mathrm{~d}$ & $1.013 \mathrm{~d}$ & $2.223 \mathrm{~d}$ & $0.779 \mathrm{~d}$ \\
\hline \multicolumn{6}{|l|}{ GO } \\
\hline 0 Control & $16.857 \mathrm{c}$ & $1293.330 \mathrm{~d}$ & $1.124 \mathrm{c}$ & $2.755 b$ & $0.798 \mathrm{c}$ \\
\hline $0.01 \%$ & $18.467 \mathrm{~b}$ & $1394.830 \mathrm{~b}$ & $1.171 \mathrm{a}$ & 3.019 a & $0.817 a$ \\
\hline $0.05 \%$ & 19.139 a & $1450.830 \mathrm{a}$ & 1.136 b & $2.807 b$ & $0.806 \mathrm{~b}$ \\
\hline $0.1 \%$ & $18.378 \mathrm{~b}$ & $1360.330 \mathrm{c}$ & $1.129 \mathrm{bc}$ & $2.761 \mathrm{~b}$ & $0.798 \mathrm{~b}$ \\
\hline
\end{tabular}

Table 3. Mean table of physiologic traits in Milk thistle affected by salt stress and GO.

\begin{tabular}{lccc}
\hline \multicolumn{1}{c}{ Treatments } & $\begin{array}{c}\text { Membranes stability } \\
\text { index (\%) }\end{array}$ & $\begin{array}{c}\text { Proline } \\
\text { (mg/g F.W.) }\end{array}$ & $\begin{array}{c}\text { Soluble carbohydrates } \\
\text { (mg/g F.W.) }\end{array}$ \\
\hline Salt stress & & & \\
\hline $0 \mathrm{dS} / \mathrm{m}$ & $65.718 \mathrm{a}$ & $1.652 \mathrm{c}$ & $64.351 \mathrm{c}$ \\
$4 \mathrm{dS} / \mathrm{m}$ & $62.787 \mathrm{~b}$ & $1.690 \mathrm{c}$ & $64.478 \mathrm{c}$ \\
$8 \mathrm{dS} / \mathrm{m}$ & $56.414 \mathrm{c}$ & $2.266 \mathrm{~b}$ & $73.409 \mathrm{~b}$ \\
$12 \mathrm{dS} / \mathrm{m}$ & $48.943 \mathrm{~d}$ & $2.772 \mathrm{a}$ & $80.466 \mathrm{a}$ \\
\hline $\mathrm{GO}$ & & & \\
\hline $0 \mathrm{Control}$ & $56.385 \mathrm{c}$ & $2.035 \mathrm{~b}$ & $69.077 \mathrm{c}$ \\
$0.01 \%$ & $62.109 \mathrm{a}$ & $2.168 \mathrm{a}$ & $72.457 \mathrm{a}$ \\
$0.05 \%$ & $58.356 \mathrm{~b}$ & $2.072 \mathrm{~b}$ & $70.367 \mathrm{bc}$ \\
$0.1 \%$ & $57.012 \mathrm{c}$ & 2.108 ab & $70.803 \mathrm{~b}$ \\
\hline
\end{tabular}

Different letters in each column for each factor indicate significant difference with using Duncan's test at $\mathrm{P} \leq 0.05$.

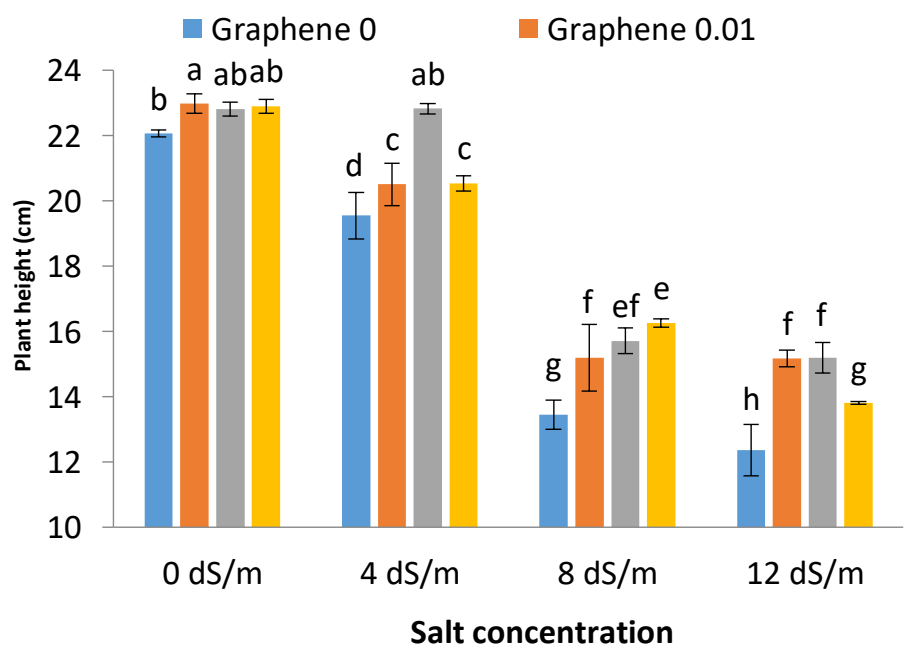

Fig 1. Effect of salt stress and exogenous GO on plant height of Milk thistle, Different letters in each column for each factor indicate significant difference with using Duncan's test at $P \leq 0.05$. Values are the mean \pm of three replications. 


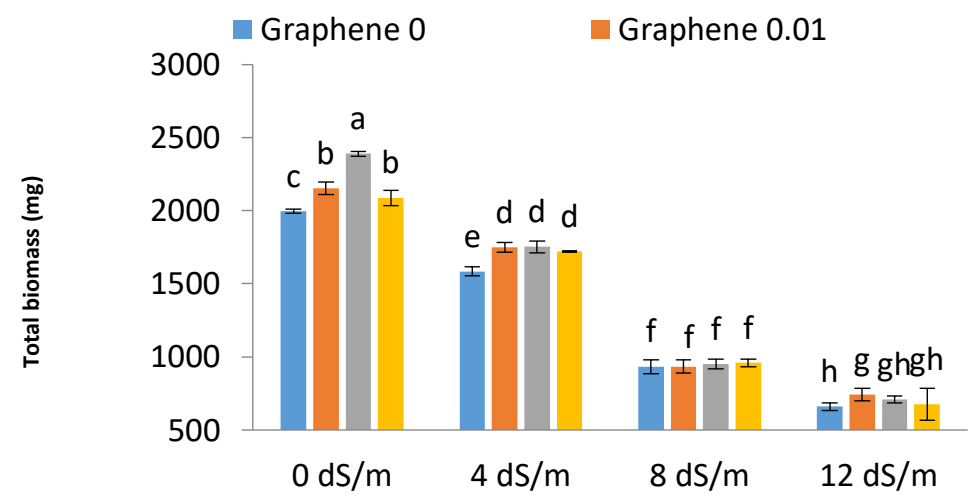

Salt concentration

Fig 2. Effect of salt stress and exogenous GO on total biomass dry weight of Milk thistle, Different letters in each column for each factor indicate significant difference with using Duncan's test at $P \leq 0.05$. Values are the mean \pm of three replications

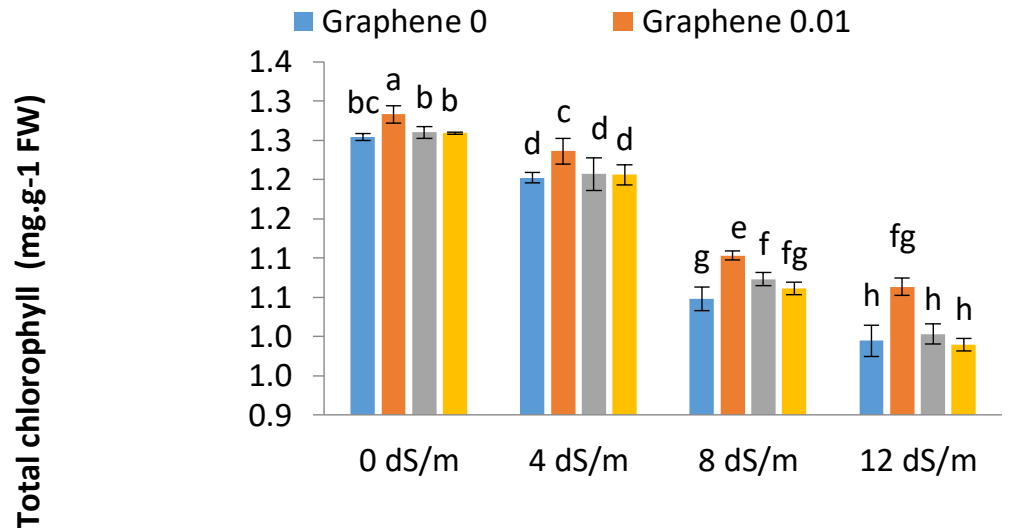

Salt concentration

Fig 3. Effect of salt stress and exogenous GO on total chlorophyll of Milk thistle. Different letters in each column for each factor indicate significant difference with using Duncan's test at $P \leq 0.05$. Values are the mean \pm of three replications

functionality when facing external disturbances (Yeilaghi et al., 2012).

\section{Proline content}

Compared to Control (non-saline) condition, an increase was seen in proline content of Milk thistle under salinity (Table 3). The maximum proline content $(2.77 \mathrm{mg} / \mathrm{g}$ F.W.) was achieved in $12 \mathrm{dS} / \mathrm{m}$ salinity stress. Also, application of GO at any concentration increased proline content compared to control (Table 3). The highest proline content of $2.17 \mathrm{mg} / \mathrm{g}$ F.W. in the leaf belonged to $0.01 \%$ GO application (Table 3). $\mathrm{Hu}$ et al., (2014) demonstrated proline increment by graphene and graphene-humic acid application in wheat plants. Anjum et al., (2014) reported that different GO concentrations either significantly increased $(0,100,200$, $1600 \mathrm{mg} / \mathrm{l} \mathrm{GO}$ ) or decrease ( $800 \mathrm{mg} / \mathrm{l} \mathrm{GO}$ ) proline content in faba bean plants. There are many reports supporting elevated proline accumulation in $B$. juncea plant tissues exposed to silver nanoparticles, under different stress conditions (Sharma et al., 2012).

\section{Soluble carbohydrates}

Salt stress enhanced soluble carbohydrates accumulation in Milk thistle leaves. The soluble carbohydrates rapidly increased after exposure to 8 and $12 \mathrm{dS} / \mathrm{m}$ salinity levels (Table 3). Furthermore, soluble carbohydrates significantly increased when GO was added to the soil (Table 3). The highest soluble carbohydrates content of $72.46 \mathrm{mg} / \mathrm{g} \mathrm{F.W}$. in Milk thistle leaves was observed in $0.01 \%$ GO treatment (Table 3). A common response to salinity stress is the decreasing of cell water potential through enhanced net concentrations of solutes or osmotic adjustment which is an important mechanism for sustaining cell water content and turgor (Chaves et al., 2003). 


\section{Materials and Methods}

\section{Experimental treatments}

The root, shoot growth and physiological characteristics of Milk thistle under salt stress were studied by using four levels of GO in soil $(0.1,0.05,0.01$ and $0 \%$ (control)). Four levels of salinity were used in the irrigation water during the growing period which maintained the electrical conductivity (EC) of soil at $12,8,4$ and $0.8 \mathrm{dS} / \mathrm{m}$ (control), respectively. Nanomaterial was purchased from Sigma-Aldrich, USA (catalog No: 806641. Graphene nanoplatelets, powder, oxidized). The physicochemical properties of GO are shown in Table 1.

\section{Statistical design and data analysis}

A pot experiment with a factorial arrangement of treatments was conducted based on a randomized complete block design (RCBD) with three replications during 2015-2016 growing period. All the data were statistically analyzed using SAS 9.1 software. The means of each trait were compared according to the Duncan multiple ranges at $p \leq 0.05$. All graphs were drawn using Excel 2010.

\section{Soil and pot preparations}

The soil in pots was collected from Research Station of College of Agriculture, University of Tehran, Karaj, Iran and then sieved to $\leq 2 \mathrm{~mm}$. The sampled field was mainly allocated to cereal crops production. The collected soil texture was loam (Sand, 34.16\%; Silt, 43.34\%; Clay, 22.5\%) with 1.70 electrical conductivity and $0.84 \%$ organic matter.

\section{Experimental procedures and measurements}

Milk thistle seed was purchased from Pakan Bazr Seed Company, Isfahan, Iran. 15 seeds of Milk thistle were sown in each plastic pot $(23 \mathrm{~cm}$ diameter $\times 24 \mathrm{~cm}$ height) containing $8 \mathrm{~kg}$ of soil, at the depth of $2 \mathrm{~cm}$. Tap water $(0.8$ $\mathrm{dS} / \mathrm{m})$ and saline water $(4,8$ and $12 \mathrm{dS} / \mathrm{m})$ were added to the pots according to the corresponding treatments to achieve 100\% FC (Field Capacity). During the experimental period, all the pots were put in a glass greenhouse under natural light. The minimum and maximum temperatures of the greenhouse were measured as 20 and $25^{\circ} \mathrm{C}$, respectively, and the relative humidity was kept at $\sim 50 \%$. After germination, plants were thinned to 5 plants per pot.

Induction of Chlorophyll a fluorescence was monitored with a handy-PEA portable fluorometer (Hansatech, UK) at 72 days after cultivation and before cutting the plants. Performance Index (PI) and Fv/Fm (maximum quantum efficiency of PSII) were measured according to Kalaji et al., (2011). Chlorophyll measurement was done following Arnon (1949) method. Membrane stability index (MSI) was determined by recording the electrical conductivity of leaf leachates (conductivity meter model WTW-LS90) in distilled water at 40 and $100^{\circ} \mathrm{C}$. Then the membrane stability was calculated using the following equation:

\section{Membrane stability index $=[1-(E C 1 / E C 2)] \times 100$}

Proline was extracted according to the method of Irigoyen et al., (1992). For the calculation of proline concentration, a standard curve was made with L-proline. Soluble sugar was measured by Schlegel (1956) method. 72 days after planting, plants with a uniform growth were chosen for measurements. At least three plants were randomly selected from each treatment replicate. The plant root and shoot were cut at the base and the biomass weight was determined. Samples were dried at $60{ }^{\circ} \mathrm{C}$ for 48 hours, and their mean root and shoot dry weight were recorded for each treatment at each replicate.

\section{Conclusion}

In the present study, total biomass, plant height, total chlorophyll, Fv/Fm ratio, performance index, and membrane stability index decreased due to salinity stress; while, the proline and soluble carbohydrates noticeably increased in the same condition. GO application modified salt stressinduced damages through increasing plant growth, plant height, chlorophyll content, photosystem efficiency, performance index, membrane stability index, and proline and soluble carbohydrates accumulation in Milk thistle plant tissues. The low concentration of GO $(0.01 \%)$ demonstrated the best results in alleviating the adverse salt stress effects. GO improved and increased cell water potential through enhancing the net concentration of solutes.

\section{Acknowledgments}

The authors would like to express their appreciation to Shahid Beheshti University for the financial support of this research project.

\section{References}

Afshar RK, Chaichi MR, Asareh MH, Hashemi M, Liaghat A (2014) Interactive effect of deficit irrigation and soil organic amendments on seed yield and flavonolignan production of Milk thistle (Silybum marianum L. Gaertn.). Ind Crops Prod. 58: 166-172.

Aken BV (2015) Gene expression changes in plants and microorganisms exposed to nanomaterials. NCBI. 33: 206219.

Ali S, Zeng F, Cai S, Qiu B, Zhang G (2011) The interaction of salinity and chromium in the influence of barley growth and oxidative stress. PSE. 57(4):153-159.

Anjum NA, Singh N, Singh MK, Sayeed I, Duarte AC, Pereira E, Ahmad I (2014) Single-bilayer graphene oxide sheet impacts and underlying potential mechanism assessment in germinating Faba bean (Vicia faba L.). Sci Total Environ. 472: 834-41.

Arnon DT (1949) Copper enzymes in isolation chloroplast phenoloxidase in (Beta vulgaris L.). Plant Physiol. 24: 1-15.

Arora S, Rajwade JM, Paknikar KM (2012) Nanotoxicology and in vitro studies: the need of the hour. Toxicol Appl Pharmacol. 258: 151-165.

Ashraf M, Foolad MR (2007) Roles of glycine-betaine and proline in improving plant abiotic stress resistance. Environ Exper Bot. 59: 206-216.

Bandurska H (2001) Does proline accumulated in leaves of water deficit stressed barley plants confine cell membrane injuries? II. Proline accumulation during hardening and its involvement in reducing membrane injuries in leaves 
subjected to severe osmotic stress. Acta Physiol Plant. 23: 483-490.

Campanelli A, Ruta C, De Mastro G, Morone-Fortunato I (2013) The role of arbuscular mycorrhizal fungi in alleviating salt stress in Medicago sativa L. Symbiosis. 59: 65-76.

Chaves MM, Maroco JP, Pereira JS (2003) Understanding plant responses to drought - from genes to the whole Funct Plant Biol. 30:239-264.

Cheng C, Liu YF, Lu GY, Zhang XK, Xie LL, Yuan CF, Xu BB (2016) Graphene oxide modulates root growth of Brassica napus $L$. and regulates $A B A$ and IAA concentration. Plant Physiol. 193: 57-63.

Geim AK (2009) Graphene: status and prospects. Sci. 324: 1530-1534.

Hasegawa PM, Bressan RA, Zhu JK, Bohnert HJ (2000) Plant cellular and molecular responses to high salinity. Plant Mol Biol. 51: 463-499.

Havaux M (1993) Rapid photosynthetic adaptation to heat stress triggered in potato leaves by moderately elevated temperatures. Plant Cell Environ. 16: 461-467.

Hu X, Mu L, Kang J, Lu K, Zhou R, Zhou Q (2014) Humic acid acts as a natural antidote of graphene by regulating nanomaterial translocation and metabolic fluxes in vivo. Environ Sci Technol. 48: 6919-6927.

Hu X, Zhou Q (2014) Novel hydrated graphene ribbon unexpectedly promotes aged seed germination and root differentiation. Sci Rep. 4: 3782.

Irigoyen JJ, Emerich DW, Sanchez-Diaz M (1992) Water stress induced changes in concentrations of proline and total soluble sugars in nodulated alfalfa (Medicago sativa) plants. Physiol Plant. 84: 55-60.

Kalaji HM, Govindjee B, Bosac K, Koscielniakd J, ZukGołaszewskae K (2011) Effects of salt stress on photosystem II efficiency and $\mathrm{CO}_{2}$ assimilation of two Syrian barley landraces. Environ Exper Bot. 73: 64-72.

Kalaji MH, Guo P (2008) Chlorophyll fluorescence: a useful tool in barley plant breeding programs. In: Sanchez A, Gutierrez SJ (Eds.). Photochemistry Research Progress. Nova Publishers, NY, USA, pp. 439-463

Karimi G, Ghorbanli M, Heidari H, Khavari Nejad RA, Assareh $\mathrm{MH}$ (2005) The effects of $\mathrm{NaCl}$ on growth, water relations, osmolytes and ion content in Kochia prostrata. Biol Plantarum. 49: 301-304.

Laruea L, Pinaultb $M$, Czarnyc B, Georgind D, Jaillard D, Bendiabf $N$, Mayne $M$, Tarand $F$, Divec $V$, Carrièrea $M$ (2012) Quantitative evaluation of multi-walled carbon nanotube uptake in wheat and rapeseed. J Hazard Mater. 155:163.

Li JG, Pu L, Han MF, Zhu M, Zhang RS, Xiang YZ (2014) Soil salinization research in China: advances and prospects. J Geogr Sci. 24: 943-960.

Loguercio C, Festi D (2011) Silybin and the liver: from basic research to clinical practice. World J Gastroenterol. 17: 2288-2301.

Nemati I, Moradi F, Gholizadeh S, Esmaeili MA, Bihamta MR (2011) The effect of salinity stress on ions and soluble sugars distribution in leaves, leaf sheaths, and roots of rice (Oryza sativa L.) seedlings. PSE. 57(1):26-33.
Nounjan N, Theerakulpisut P (2012) Effects of exogenous proline and trehalose on physiological responses in rice seedlings during salt-stress and after recovery. PSE. 58(7):309-315.

Parisi C, Vigani M, Rodri guez-Cerezo E (2015) Agricultural Nanotechnologies: what are the current possibilities? Nano Today. 10: 124-127.

Park HJ, Kim SH, Kim HJ, Choi SH (2006) A new composition of nano-sized silica-silver for control of various plant diseases. Plant Pathol. 22: 295-302.

Ren W, Chang C, Teng Y (2016) Sulfonated graphene induced hormesis is mediated through oxidative stress in the roots of maize seedlings. Sci Total Environ. 572: 926-934.

Rohacek K (2012) Chlorophyll fluorescence parameters: the definitions, photosynthetic meaning, and mutual relationship. Photosynthetica. 40: 13-29.

Rosa GDL, García-Castaneda C, Vazquez-Núnez E, AlonsoCastro AJ, Basurto-Islas G, Mendoza A, Cruz-Jimenez G, Molina C (2016) Physiological and biochemical response of plants to engineered NMs: Implications on future design. Plant Physiol Biochem. 110: 226-235.

Schlegel H G (1956) Die Verwertung organischer sauren durch chlorella in lincht. Planta. 47: 510-515.

Sharma P, Bhatt D, Zaidi MGH, Saradhi PP, Khanna PK, Arora $S$ (2012) Silver nanoparticle-mediated enhancement in growth and antioxidant status of Brassica juncea. Appl. Biochem Biotechnol. 167: 2225-2233.

Sun JK, Li T, Xia JB, Tian JY, Lu ZH, Wang RT (2011) Influence of salt stress on ecophysiological parameters of Periploca sepium Bunge. Plant, Soil, and Environ. 57(4): 139-144.

Taffouo VD, Wamba OF, Yombi E, Nono GV, Akoa A (2010) Growth, yield, water status, and ionic distribution response of three Bambara groundnuts (Vigna subterranean L.) verdc. Landraces grown under saline conditions. Int. J Botany. 6: 53-58.

Torney F, Trewyn BG, Lin VSY, Wang K (2007) Mesoporous silica nanoparticles deliver DNA and chemicals into plants. Nat Nanotechnol. 2: 295-300.

Turan MA, Turkmer N, Taban N (2007) Effect of $\mathrm{NaCl}$ on stomatal resistance and proline chlorophyll, $\mathrm{NaCl}$ and $\mathrm{K}$ concentrations of lentil plants. J Agron. 6: 378-381.

Venkatachalam P, Priyanka N, Manikandan K, Ganeshbabu I, Indiraarulselvi $\mathrm{P}$, Geetha N, Muralikrishna K, Bhattacharya RC, Tiwari M, Sharma N, Sahi SV (2016) Enhanced plant growth promoting the role of phycomolecules coated zinc oxide nanoparticles with $P$ supplementation in cotton (Gossypium hirsutum L.). PPB. 110:118-127.

Yeilaghi $H$, Arzani A, Ghaderian $M$, Fotovat R, Feizi $M$, Pourdad SS (2012) Effect of salinity on seed oil content and fatty acid composition of safflower (Carthamus tinctorius L.) genotypes. Food Chem. 130: 618-625.

Yusuf M, Hasan SA, Ali B, Hayat S, Fariduddin Q, Ahmad A (2007) Effect of salicylic acid on salinity-induced changes in Brassica juncea. Integr Plant Biol. 50(9):1096-1102.

Zhang M, Gao B, Chen J, Li Y (2015) Effects of graphene on seed germination and seedling growth. J Nanopart Res. 17: 78.

Zhu JK (2001) Plant salt tolerance. Trends Plant Sci. 6: 66-71. 